\title{
The 2D:4D ratio and Myopic Loss Aversion (MLA): An Experimental Investigation
}

\author{
Anderson Mutter Teixeira - FACE-UFG \\ andersonmutterteixeira@gmail.com \\ Benjamin M. Tabak - UCB \\ benjaminm.tabak@gmail.com \\ Daniel O. Cajueiro - UNB \\ danielcajueiro@gmail.com
}

Faculty of Administration, Accounting and Economy, Universidade Federal de Goiás, FACE-UFG, CEP 74.001-970, Goiânia, Brazil

Department of Economics and Law and Economics, Universidade Católica de Brasília , CEP 70790-160 Brasília, DF, Brazil

Department of Economics, Universidade de Brasília, FACE, CEP 70910-900, Brasília, DF, Brazil

National Institute of Science and Technology for Complex Systems, Universidade de Brasília, FACE, CEP 70910-900, Brasília-DF, Brazil

\section{Resumo}

A myopic loss aversion (MLA) é considerado ser uma das principais explicações do comportamento de aversão ao risco, bem como, para o Equity Premium Puzzle (Mehra e Prescott 1985). Nesse artigo mostramos que uma maior exposição ao hormônio testosterona influencia a MLA, e que a razão 2D:4D é o melhor preditor biológico.

Palavra-chave: Risco, Experimento, Testosterona

\section{Abstract}

Myopic loss aversion (MLA) is considered to be one of the main explanations of people's aversion to risk as well as for the Equity Premium Puzzle (Mehra and Prescott 1985) In this letter, we show that greater exposure to testosterone influences MLA, and also that the 2D:4D ratio is the best predictor among other biological factors.

Keywords: Risk, Experiment, Testosterone.

JEL classification: C9, D81

Área 8 - Microeconomia, Métodos Quantitativos e Finanças 


\section{Introdução}

One of the greatest economic puzzles is the Equity Premium Puzzle (EPP). For Mehra and Prescott (1985), the EPP is associated with the high risk premium demanded by investors for holding assets of US companies in their portfolios. The Myopic Loss Aversion (MLA) drawn up by Bernatzi and Thaler (1995) is a theoretical concept used to explain this puzzle. It is the result of two behavioral concepts. The first is the concept that people are more sensitive to losses than to gains of the same magnitude (Kahneman and Tversky, 1979), which is known as the so-called loss aversion. The second, the Mental Accounting concept, shows how people encode and evaluate economic events (Thaler, 1985).

In order to build an experimental design to test MLA, Bernatzi and Thaler (1995) suggest the simultaneous manipulation of the information set on portfolio performance and flexibility of choice in order to reduce risk perception. Based on this framework, experiments have been carried out to provide evidence of the existence of MLA [Gneezy and Potters (1997), Bellemare et al. (2005), Haigh and List (2005), Sutter (2007)].

There is currently an expanding body of literature emphasizing that the level of testosterone exposure influences human behavior and economic outcomes. This influence is associated with the 2D:4D ratio biomarker. Manning et al. (1998), Manning (2002), and McIntyre (2006) defined the marker of higher fetal exposure to testosterone as the ratio of the length between the second and fourth fingers. A lower 2D:4D ratio indicates a higher exposure to testosterone. In fact, Manning et al. (1998) confirmed the existence of a sexual dimorphic standard between genders, with men having lower 2D:4D ratios than women. In addition, McIntyre (2006) and Honekopp and Watson (2010) claim that this difference is already established in children by the age of two.

Few papers have explored the relationship between this biomarker and economic issues. In particular, Apicella et al. (2008), Coates et al. (2009), Garbarino et al. (2011), Branas-Garsa andRustichini (2011) focusing on risk aversion show that people with lower 2D:4D ratios are less risk averse. In this paper, we investigated whether MLA can be influenced by the 2D:4D ratio. After this introduction, Section 2 describes the experimental procedures while the results are presented in Section 3. Finally, Section 4 presents the conclusions of this work.

\section{Experiment Design}

The experiment was built upon the design introduced by Gneezy and Potters (1997). The subjects were divided into two groups in accordance with the treatments. In the $\mathrm{H}$ treatment (High Information), the subjects received feedback on their results, and were free to change their choices after each of the nine rounds of the experiment. In the L treatment (Low Information), the stakes were fixed and were the same for every three rounds. At the end of three rounds, the subjects received feedback on the results obtained and were free to change their choices. 
Before the experiment, subjects were endowed with 100 monetary units. They then had to decide how much of this amount would be gambled in a lottery which offered a two-thirds (67\%) chance of losing the allocated amount, and a one-third (33\%) chance of winning 2.5 times the amount gambled.

The experiment conducted with undergraduate students at the Universidade Federal de Goiás ${ }^{12}$ was carried out by computer. A total of 8 experimental sessions were held, 4 for each treatment. In all, 87 volunteers attended the experiment, 46 in the $\mathrm{H}$ treatment, 11 of whom were women and 35 men, while 41 volunteers participated in the $\mathrm{L}$ treatment, 12 being women and 29 men.

Each session lasted about 55 minutes. Subjects were invited to participate with an announcement that highlighted the time, place and the chance to win a payo_ of up to $\mathrm{R} \$ 20.00$ (roughtly $\$ 10.00$ ).

\section{Results}

The 2D:4D ratio was measured using the AutoMetric 2.2 software developed by Debruine (2004). The measurement confirmed a sexual dimorphic relation between genders. The males presented a lower ratio than females. In the $\mathrm{H}$ treatment, the average 2D:4D ratio for the right hand was 1.002 for females, and 0.977 for males $(t=2.002, p$ $=0.051)$. In the L treatment, the average 2D:4D ratio was 0.992 for females, and 0.964 for males $(t=1.867, p=0.071)$.

Result 1 - For subjects of both genders and for males with a lower 2D:4D ratio (suggesting high exposure to testosterone) the results confirm the incidence of MLA.

Tables 1 and 2 show the average amount gambled by subjects with higher and lower 2D:4D, and also the Mann-Whitney test. In accordance with the Mann-Whitney statistical test, it was only possible to confirm the incidence of MLA for individuals with a lower 2D:4D ratio, given the significant di_erence in the average amount gambled for all comparison blocks.

According to Table 1, the average amount gambled by subjects of both genders with lower ratios in the $\mathrm{H}$ treatment was 50.17, while in the $\mathrm{L}$ treatment it was 68.57 (p $=0.0059$ - Mann- Whitney test). Based on Table 2, for males with lower 2D:4D ratios, the average amount gambled in the $\mathrm{H}$ treatment was 51.49 , and 72.22 in the $\mathrm{L}$ treatment $(\mathrm{p}=0.050$ - Mann-Whitney test).

The same procedure was performed for women, but the results were not significant, and so were not presented here. These results confirm the MLA hypothesis, as shown by Thaler (1985), Gneezy and Potters (1997), Haigh and List (2005), and others. Thus, the aggregation of results through informational limitation, and the reduction of flexibility of choice contributed towards the reduction in risk perception of the subjects. Furthermore, for subjects with lower 2D:4D ratios, the effect was enhanced by greater exposure to testosterone. These results are in line with those found by Coates et al. (2009), Garbarino et al. (2011) and Branas-Garsa and Rustichini (2011), which show that subjects with lower 2D:4D ratios are more prone to risk.

\footnotetext{
${ }^{1}$ This is considered one of the most important universities of the Brazilian Central West.

2 The study was approved by the Research Ethics (UNB, CEP - IH. CAAE. 13140713.6.0000.5540).
} 
Table 1. Average value gambled in $\mathrm{H}$ and $\mathrm{L}$ treatments - both genders

\begin{tabular}{ccccccc}
\hline & \multicolumn{2}{c}{ Higher 2D:4D } & \multicolumn{2}{c}{ Lower 2D:4D } & \multicolumn{2}{c}{ Mann-Whitney Test } \\
\hline & $\mathrm{H}$ & $\mathrm{L}$ & $\mathrm{H}$ & $\mathrm{L}$ & $\mathrm{H}$ Higher & Lower \\
& & & & & 2D:4D & 2D:4D \\
\hline Rounds 1-3 & 41.32 & 46.53 & 48.15 & 63.19 & 0.427 & 0.0236 \\
& $(26.68)$ & $(23.66)$ & $(25.81)$ & $(24.04)$ & & \\
Rounds 4-6 & 40.35 & 46.33 & 53.20 & 68.11 & 0.4054 & 0.0311 \\
& $(30.29)$ & $(22.07)$ & $(26.25)$ & $(21.67)$ & & \\
Rounds 7-9 & 40.51 & 50.53 & 55.76 & 74.30 & 0.2263 & 0.0070 \\
& $(30.56)$ & $(26.18)$ & $(26.26)$ & $(25.55)$ & & \\
Rounds 1-9 & 40.75 & 47.73 & 50.17 & 68.57 & 0.3450 & 0.0059 \\
& $(47.73)$ & $(20.59)$ & $(24.17)$ & $(17.05)$ & & \\
\hline
\end{tabular}

Standard deviation in parentheses.

Table 2. Average value gambled in $\mathrm{H}$ and $\mathrm{L}$ treatments - males

\begin{tabular}{ccccccc}
\hline & \multicolumn{2}{c}{ Higher 2D:4D } & \multicolumn{2}{c}{ Lower 2D:4D } & \multicolumn{2}{c}{ Mann-Whitney Test } \\
\hline & $\mathrm{H}$ & $\mathrm{L}$ & $\mathrm{H}$ & $\mathrm{L}$ & $\begin{array}{c}\text { Higher } \\
\text { 2D:4D }\end{array}$ & $\begin{array}{c}\text { Lower } \\
\text { 2D:4D }\end{array}$ \\
\hline & & & & $\mathrm{H}$ vs L & H vs L \\
\hline Rounds 1-3 & 36.59 & 46.00 & 46.58 & 66.57 & 0.3286 & 0.0008 \\
& $(29.47)$ & $(22.82)$ & $(26.58)$ & $(25.39)$ & & \\
Rounds 4-6 & 34.24 & 50.62 & 52.11 & 70.28 & 0.2296 & 0.0027 \\
& $(29.64)$ & $(25.82)$ & $(27.59)$ & $(23.14)$ & & \\
Rounds 7-9 & 40.94 & 50.00 & 55.57 & 82.23 & 0.5038 & 0.0005 \\
& $(37.45)$ & $(22.99)$ & $(28.81)$ & $(18.99)$ & & \\
Rounds 1-9 & 36.91 & 48.85 & 51.49 & 72.22 & 0.2747 & 0.0050 \\
& $(32.98)$ & $(20.58)$ & $(24.06)$ & $(16.35)$ & & \\
\hline
\end{tabular}

Standard deviation in parentheses.

Result 2 - The 2D:4D ratio is the unique biological predictor for determining behavior differences in gender (male) and in both genders in the case of the MLA hypothesis.

Table 3 shows the OLS estimates for the linear regression model associated with the MLA experiment. It confirms that there is a relationship between the 2D:4D ratio and the average amount gambled by subjects. The negative sign of the parameter that relates these two variables is in line with [Coates et al. (2009), Branas-Garsa and Rustichini (2011) and Garbarino et al. (2011)]. It suggests an inverse relationship between the 2D:4D ratio and the average amount gambled. A $1 \%$ decrease in the 2D:4D ratio (higher exposure to testosterone) was associated with a $5.07 \%$ increase in the average amount gambled. 
Table 3 also shows that the relation between the average amount gambled and the 2D:4D ratio is not spurious and cannot be explained by other biological variables commonly used in the literature [Apicella et al. (2008), Coates et al. (2009) and Garbarino et al. (2011)]. Biological variables such as gender, race, laterality (being right or left handed), weight and height are not significant. Thus the 2D:4D ratio is found to be the unique biological predictor to infer the relationship between the average amount gambled and biological factors.

Table 3: Estimates of OLS for the MLA experiment

\begin{tabular}{|c|c|c|}
\hline & (1) & $(2)$ \\
\hline Constant & $\begin{array}{l}3.792 * * * \\
(0.0724)\end{array}$ & $\begin{array}{l}3.899 * * * \\
(1.3245)\end{array}$ \\
\hline 1.2D:4D Right & $\begin{array}{l}-5.076 \text { *** } \\
(1.2789)\end{array}$ & $\begin{array}{l}-4.640 * * * \\
(1.3405)\end{array}$ \\
\hline Dummy gender & & $\begin{array}{l}0.056 \\
(0.1721)\end{array}$ \\
\hline Dummy white & & $\begin{array}{l}0.166 \\
(0.1173)\end{array}$ \\
\hline Dummy laterality & & $\begin{array}{l}0.323 \\
(0.3425)\end{array}$ \\
\hline Height & & $\begin{array}{l}-0.217 \\
(0.9084)\end{array}$ \\
\hline Weight & & $\begin{array}{l}-0.002 \\
(0.0046)\end{array}$ \\
\hline $\mathrm{N}$ & 85 & 85 \\
\hline LnL & -63.213 & 61.287 \\
\hline $\mathrm{R}$ & 0.136 & 0.174 \\
\hline $\mathrm{F}$ & 15.755 & 3.569 \\
\hline
\end{tabular}

Standard deviation in parentheses. 2D:4D ratio variable and the average amount gambled were normalized using a logarithmic transformation

\section{Conclusion}

We conclude that the 2D:4D ratio influences the incidence of MLA. Higher testosterone exposure reinforces the experiment design by Gneezy and Potters (1997) through the high average amount gambled in the $\mathrm{L}$ treatment. The second result confirms the 2D:4D ratio is the unique factor biological for explaining the behavioral di_erences between genders in the MLA experiment.

\section{Appendix - Supplementary Material}

\subsection{Overall Procedure: The MLA Experiment and the 2D:4D Ratio}

The experiment was conducted with undergraduate students recruited at the Federal University of Goiás (UFG). The experiments were carried out on 24 computers in optimal conditions at the University's computer laboratory. 
All the experimental procedures were carried out on the computers with the use of a specific program. This made it possible to facilitate the procedure. As volunteers selected the amounts they wanted to bet on the financial lotteries, the program registered the amounts bet, the time taken to make a decision by lottery, the returns by round, the amount accrued during the experiment according the rule for each treatment.

The experiments were conducted between 2 and 17 October, 2013. The lowest number of participants per session was five volunteers and the highest was 24 participants.

The duration of the experiment depended on the number of participants per session. The average duration of the sessions was 55 minutes, with the initial 20 minutes given to read the instructions, respond a questionnaire on biological and social data, and to participate in the financial lotteries. The remaining time was used to collect photocopies of the volunteers' left and right hands, to sign the Term of Free and Informed Consent (TCLE) ${ }^{3}$ and to draw the winners. Participants' questions were addressed individually.

Participants were recruited through an announcement distributed on the campus stating the dates and times of an experiment offering the chance of winning up to $\mathrm{R} \$ 20.00$ reais. (Approximately U\$\$10.00). At the set times, volunteers were asked to take a seat in front of a computer. The MLA was divided into 3 stages. In the first, the participants, after reading the instructions, answered a questionnaire with questions regarding certain biological and social characteristics.

In the second part, the persons recruited participated in the successive financial lotteries of the experimental treatments, and in the third participants had photocopies taken of both their left and right hands and also signed the Term of Consent. Lastly, the winning participants were drawn.

\subsection{Specific procedure: The 2D:4D ratio}

A proxy, called the 2D:4D ratio, was used to determine the influence of hormones on the behavior of economic agents when making choices involving risk and uncertainty.

With the use of a scanner, images were captured of volunteers' both left and right hands. A second image was taken of the hands if the first images were not clear. Participants were also asked to remove rings from their fingers.

\footnotetext{
${ }^{3}$ Document of the Research Ethics Committee.
} 
Each image was given an identification number, which was the lottery number (record) answered by the respective participant. The scanner used was a HP Scanjet G4050, with a digital resolution of up to $4800 \times 9600$ dpi.

The use of scanned images of the hand (scanner) is a procedure that has been reported in the literature. The software used to measure the index (2D) and ring fingers (4D) was AutoMetric 2.2 developed by DeBruine $(2004)^{4}$. This software allows the exact measurement of the 2D:4D ratio, and has been used by Garbarino and Sydnor (2011).

\subsection{Instructions for the MLA Experiment: The H Treatment}

Thank you for participating in our experiment on choices made in a situation of uncertainty (decision making). We kindly request that you carefully read the instructions of the experiment.

We ask that you do not communicate with the other participants at any time during the experiment. Please turn off your cell phone, iPad, or any other communication device you may have.

Do not look at the choices made by the other participants, to keep you from influencing the choices of others, and others from influencing yours. If you have any doubts, raise your hand and a proctor will answer your question individually.

The experiment will be carried out in three stages. In the first stage, you will answer a questionnaire on certain biological and social traits. In the second stage, you will make bets in the rounds of the experiment. In the third phase, when you are finished betting in the rounds of the experiment, you will raise your hand so that the proctor may take photocopies of both your left and right hands.

A second photocopy may be have to made is the first is not clear, and you will be asked to remove any rings or objects from your hands. At the end of this stage, participants will be randomly selected to receive the amount accrued during the experiment.

The experiment will take approximately 55 minutes. You must follow the instructions closely, and if you do so, you may win a cash prize.

The experiment consists of 10 rounds in the same lottery. The first round will be a practice round and will not count towards the experiment, but the remaining 9 rounds will. In each of the nine rounds, each participant will receive the amount of 100 m.u. (monetary units), and must decide how much of this amount will allocated to the lottery below:

You have two chances in three $(67 \%)$ of losing the amount you decided to bet and/a one-third chance of (33\%) winning 2.5 the amount bet.

\footnotetext{
${ }^{4}$ For more details on the software: facelab.org/debruine/Programs/autometric.php
} 
In each round, the participant shall enter the amount they wish to bet in the lottery and confirm the bet. The wins or losses will depend on the letter chosen by each participant at the beginning of the game. The options are A, B or C. The letter chosen by each participant will remain the same in all nine rounds of the experiment.

A participant will be considered a winner if the respectively chosen letter matches the letter randomly chosen by the program, and considered a loser if it does not. Each letter has a $1 / 3$ chance $(33 \%)$ of being drawn and, after the bets are placed, the program then performs the drawing. Therefore, the probability of winning is $33 \%$ or $1 / 3$ and the probability of losing is $67 \%$ or $2 / 3$.

Regarding the possible wins in the experiment, the participant that is drawn will receive 2.5 times the amount bet, in addition to the $100 \mathrm{~m}$.u. allotted at the beginning of the round.

In the subsequent round, you will again be allotted 100 u.m., and must decide how much of this amount you wish to bet in the lottery. The program will inform you of the wins in each round, and the amount accrued in all rounds.

Two monetary units are equal to $\mathrm{R} \$ 0.01$ (one centavo) and thus $100 \mathrm{u}$.m. are equal to fifty centavos of real $(\mathrm{R} \$ 0.50)$.

Keep in mind that the letter chosen is always the same, but the letter drawn in each round may change. At the end of the experiment, your wins will be added up, and this will be the amount of the prize in the draw that will take place at the end of the experiment. Therefore, in a random way, through a drawing, 10\% of the participants will win the accrued prize.

\subsection{Instructions for the MLA Experiment: The L Treatment}

Thank you for participating in our experiment on choices made in a situation of uncertainty (decision making). We kindly request that you carefully read the instructions of the experiment.

We ask that you do not communicate with the other participants at any time during the experiment. Please turn off your cell phone, iPad, or any other communication device you may have.

Do not look at the choices made by the other participants, to keep you from influencing the choices of others, and others from influencing yours. If you have any doubts, raise your hand and a proctor will answer your question individually.

The experiment will be carried out in three stages. In the first stage, you will answer a questionnaire on certain biological and social traits. In the second stage, you will make bets in the rounds of the experiment. In the third phase, when you are finished betting in the rounds of the experiment, you will raise your hand so that the proctor may take photocopies of both your left and right hands. 
A second photocopy may be have to made is the first is not clear, and you will be asked to remove any rings or objects from your hands. At the end of this stage, participants will be randomly selected to receive the amount accrued during the experiment.

The experiment will take approximately 55 minutes. You must follow the instructions closely, and if you do so, you may win a cash prize.

The experiment consists of 10 rounds in the same lottery. The first round will be a practice round and will not count towards the experiment, but the remaining 9 rounds will. In each of the nine rounds, each participant will receive the amount of 100 m.u. (monetary units), and must decide how much of this amount will allocated to the lottery below:

\section{You have two chances in three $(67 \%)$ of losing the amount you decided to bet and a one-third chance of $(33 \%)$ winning 2.5 the amount bet.}

The participant shall make his or her choice at every three rounds, and the amounts defined for each group of 3 rounds shall remain the same for the 3 rounds of that group. Suppose a participant wishes to bet X m.u. (monetary unit) in round 1. This means that you will also have decided to bet the same amount (X m.u.) for rounds 2 and 3 . Thus, the choice made for round 1 cannot be changed for the subsequent rounds 2 and 3 .

This same rule applies for round 4 , and the amount bet in that round shall remain the same for rounds 5 and 6 . Lastly, the amount bet in round 7 shall remain the same for the last two rounds, 8 and 9.

The program will inform the round you are currently playing in and shall decide and enter the amount you wish to bet. Remember that the amount bet shall remain the same for the two subsequent rounds.

Participants will have to choose a registry letter at the beginning of the experiment from one of the following options: A, B or C. The letter chosen by a participant shall remain the same for all 9 rounds of the experiment.

A participant will be considered a winner if the respectively chosen letter matches the letter randomly chosen by the program, and considered a loser if it does not. Each letter has a $1 / 3$ chance $(33 \%)$ of being drawn and, after the bets are placed, the program then performs the drawing. Therefore, the probability of winning is $33 \%$ or $1 / 3$ and the probability of losing is $67 \%$ or $2 / 3$.

Regarding the possible wins in the experiment, the participant that is drawn will receive 2.5 times the amount bet, in addition to the 100 m.u. allotted at the beginning of the round. 
Two monetary units are equal to $\mathrm{R} \$ 0.01$ (one centavo) and thus $100 \mathrm{~m}$.u. are equal to fifty centavos of real $(\mathrm{R} \$ 0.50)$.

Keep in mind that the letter chosen is always the same, but the letter drawn in each round may change. At the end of the experiment, your wins will be added up, and this will be the amount of the prize in the draw that will take place at the end of the experiment. Therefore, in a random way, through a drawing, 10\% of the participants will win the accrued prize.

\subsection{Biological and Social Trait Questionnaire}

1. Your full name:

2. Your age:

3. Your date of birth:

4. Your gender: ( ) Male ( ) Female

5. Your ethnicity: ( ) White, ( ) Black, ( ) Mixed, ( ) Asian or Indigenous

6. Your height:

7. Your weight:

8. If you are left ( ) or right-handed ( ):

9. Your major:

10. Your current semester:

\section{Referências}

Apicella, C., Dreber, A., Capbell, B., Gray, P., Ho_man, M., and Little, A. (2008). Testosterone and financial preferences. Evolution and Human Behavior, 29:384-390.

Bellemare, C., Krause, M., Kroger, S., and Zhang, C. (2005). Myopic loss aversion: information feedback vs investment flexibility. Economic Letters, 78:319-324.

Bernatzi, S. and Thaler, R. (1995). Myopic loss aversion and the equidity premium puzzle. The Quarterly Journal of Economics, 110:73-92.

Branas-Garsa, P. and Rustichini, A. (2011). Organizing e_ects of testosterone and economic behavior. Plos one, 6:1-8.

Coates, J., Gurnell, M., and Rustichini, A. (2009). Second-to-forth digit ratio predicts success among high-frequency financial traders. PNAS, 106:623-628.

Debruine, L. M. (2004). Autometric software for measurement of $2 \mathrm{~d}: 4 \mathrm{~d}$ ratios, from http://facelab.org/debruine/programs/autometric.php, accessed august 25, 2012. 
Garbarino, E., Slonim, R., and Sydnor, J. (2011). Digit ratios (2d:4d) as predictors of risky decision making for both sexes. Journal of Risk and Uncertainty., 42:1-46.

Gneezy, U. and Potters, J. (1997). An experiment on risk taking and evaluation periods. The Quarterly Journal of Economics, 112:631-645.

Haigh, M. and List, J. A. (2005). Do professional traders exhibit myopic loss aversion? an experimental analysis. The Journal of Finance, 60:523-534.

Honekopp, J. and Watson, S. (2010). Meta-analysis of digit ratio 2d:4d shows greater sex difference . American Journal of Human Biology, 22:619-630.11

Kahneman, D. and Tversky, A. (1979). Prospect theory of decision under risk. Econometrica, 47:263-291.

Manning, J., Scutt, D., Wilson, J., and Lewis-Jones, D. (1998). The ratio of the 2nd 4th digit length: a predictor od sperman numbers and concentrations of testosterone, luteinizing hormone and oestrogen. Human Reproduction, 13:3000-30004.

Manning, J. M. (2002). Digit Ratio: A Pointer to Fertility, Behavior and Health. Rutgers University Press.

McIntyre, M. (2006). The use of digit ratios as markers for perinatal androgen action. Reproductive Biology and Endocrinology., 26.

Mehra, R. and Prescott, E. (1985). The equitiy premium: A puzzle. Journal of Monetary Economics., 15:145-161.

Sutter, M. (2007). Are teams prone to myopic loss aversion? an experimental study on individual versus team investment behavior. Economics Letters., 97:128-132.

Thaler, R. (1985). Mental accounting and consumer choice. Marketing Science., 4:199-214. 